\title{
Persistent atrial standstill in familial Ebstein's anomaly
}

\author{
LUC A PIERARD, LUC HENRARD, JEAN-CLAUDE DEMOULIN \\ From the Department of Cardiology, Institute of Medicine, University Hospital, Liège, Belgium
}

SUMmaRY Persistent atrial standstill occurred in a father and his youngest son with familial Ebstein's anomaly. In both cases routine electrocardiograms showed no atrial electrical activity and cross sectional echocardiograms showed inferior displacement of the septal tricuspid leaflet and tethering of the tricuspid leaflets to the right ventricle. The father had a cerebral embolism and died of a myocardial infarction. Necropsy showed attachment of the septal tricuspid leaflet below the membranous septum. On serial histological examination fibrofatty infiltration of the right atrial wall, the atrioventricular node, and the inferior part of the His bundle up to the bifurcation was present. The son had haemodynamic and electrophysiological findings consistent with mild Ebstein's anomaly and persistent atrial standstill, for which permanent cardiac pacing was necessary.

The persistent atrial standstill with slow escape rhythm was most probably a consequence of the abnormalities in both the atrial wall and the His bundle which, together with the abnormal attachment of the tricuspid valve, may be features of the same congenital cardiac anomaly.

Ebstein's anomaly is an uncommon congenital heart disorder ${ }^{1}$ predisposing to right bundle branch block, pre-excitation, ${ }^{2}$ and an increased risk of sudden cardiac death. ${ }^{34}$ Atrial fibrillation occurs in one third of patients with Ebstein's anomaly ${ }^{3}$ but to our knowledge atrial standstill has never been reported in this condition. A familial occurrence has been reported independently for atrial standstill ${ }^{5-7}$ and for Ebstein's anomaly..$^{8-10}$

We report the rare association of familial Ebstein's anomaly and persistent atrial standstill in a father and son.

\section{Patients and methods}

CASE 1

A 31 year old man presented in 1956 with transient aphasia and right hemiparesis. Two other episodes of aphasia occurred during the following years, and he was referred to a physician in 1964 because of a return of the right hemiparesis and aphasia, which were slow to improve.

Requests for reprints to Dr Luc Piérard, Service de Cardiologie, Université de Liège, 59 Boulevard de la Constitution, B-4020 Liège, Belgium.

Accepted for publication 26 November 1984
Physical examination showed a regular pulse of 48 beats/min, normal heart sounds, and a slight right facial paresis. The electrocardiogram showed junctional regular rhythm with left $\mathrm{QRS}$ axis deviation and absent initial septal forces. No $P$ waves were visible (Fig. 1). An intra-atrial electrogram detected no atrial electrical activity. The escape rhythm was atrioventricular junctional at a regular rate of 50 beats/min.

Right heart catheterisation showed no "a" waves in the right atrial pressure tracings. No atrial wall movement was observed at fluoroscopy. No angiogram was performed.

The patient was discharged taking oral anticoagulants. Simultaneous $M$ mode echocardiograms of the tricuspid and mitral valves were recorded from the parasternal transducer position, and tricuspid valve closure followed mitral valve closure with an interval of $50 \mathrm{~ms}$. There was no A wave on the mitral and tricuspid valve echocardiograms. A cross sectional echocardiogram in the apical and subcostal four chamber views showed an abnormally low septal insertion of the septal tricuspid leaflet, enlargement of the right atrium, increased redundance of the tricuspid subvalvar apparatus, and tethering of the leaflets. In July 1981 he had an anteroseptal myocardial infarction and died as a result of cardiogenic shock. At necropsy no thrombus was found in the coronary arteries. A large infarct of the septal and anterior wall 


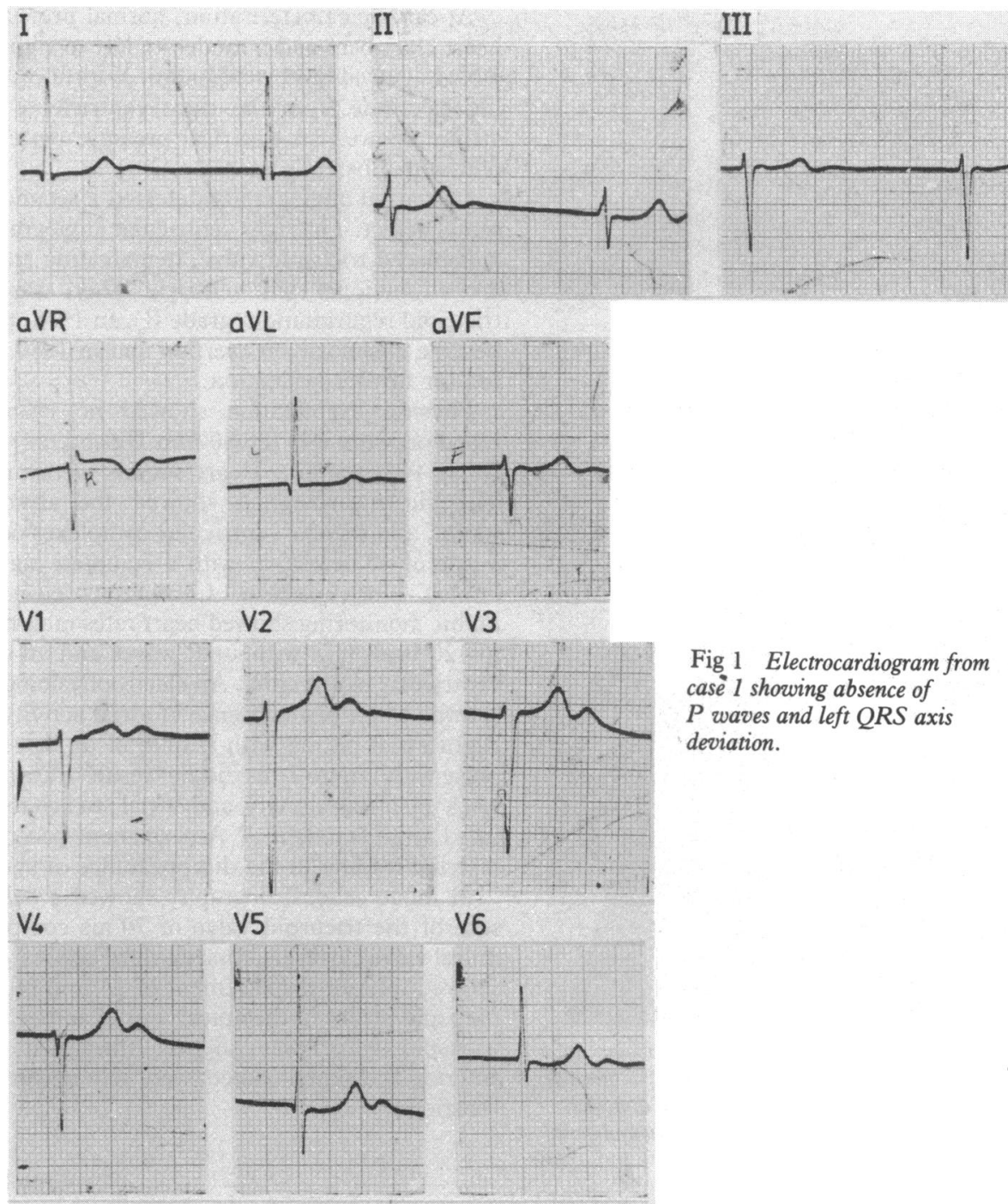

was present with a septal rupture of $3 \mathrm{~cm}$ in diameter obstructed by a thrombus extending into the right ventricle. The septal leaflet of the tricuspid valve was attached to the ventricle $1 \mathrm{~cm}$ below the membranous septum (Fig.2).

Histological examination of the heart was performed. The sinoatrial and atrioventricular nodes and their approaches, the atrioventricular bundle, and bundle branches were serially sectioned perpendicular to the long axis of the sinoatrial node and of the His bundle. Every tenth section was retained. Alternate sections were stained with haematoxylin and eosin and the Azan-Heidenhain (variation of MassonTrichrome) stain. ${ }^{11}$ There were 350 sections in the sinus node and 1500 sections in the atrioventricular bundle region. Microscopical examination showed a fresh infarct and diffuse fibrotic scars in both ventricles. The right atrial watl was almost completely replaced by fibrofatty infiltration, and there was no distinct sinus node structure. Fibrofatty infiltration was seen in the approaches of the atrioventricular node. The compact atrioventricular node, with disorganised cells, was located to the right of the central fibrous body. The atrioventricular bundle was at the ventricular level, on the right, above the tricuspid connection.

Slightly fatty fibrosis was found on the inferior part of the His bundle. This fatty fibrosis was increasingly 


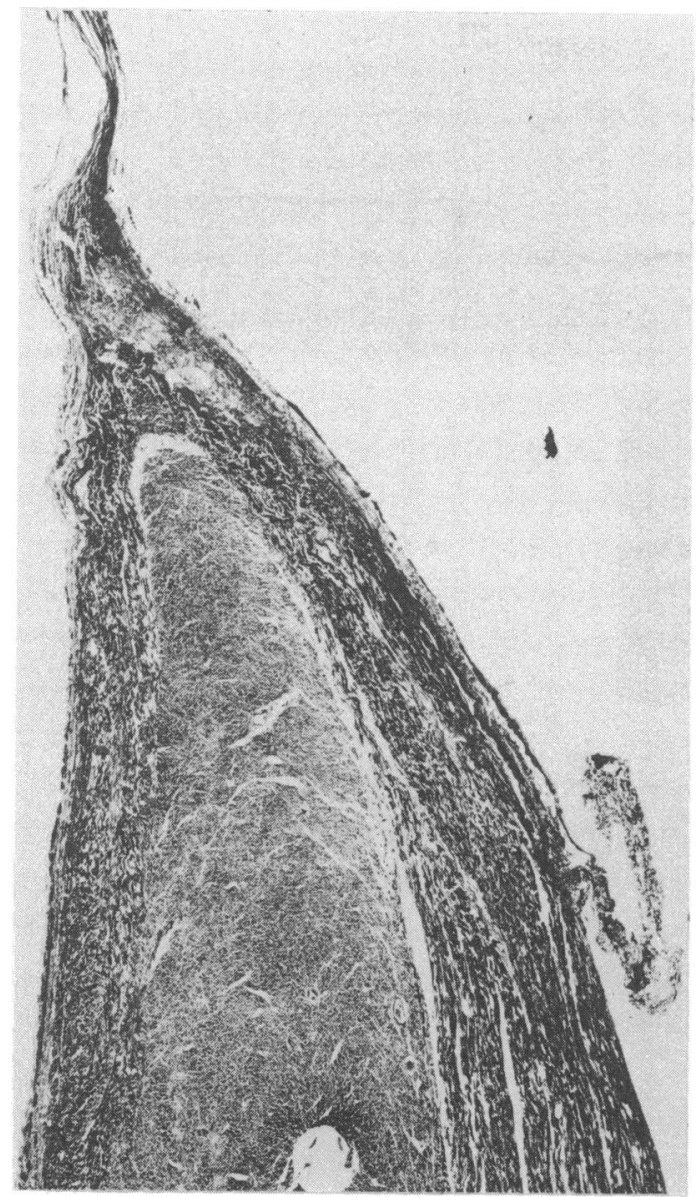

Fig 2 Case 1: histological section of the atrioventricular junction at the level of bifurcation. The His bundle is at the upper right of the muscular septum. The tricuspid valve is attached $1 \mathrm{~cm}$ below the membranous septum. (Haematoxylin and eosin $\times 7$, original magnification.)

evident and became subtotal at the end of the bifurcation. The left main bundle was intact, but an interruptive fibrosis was seen in its anterior and septal ramifications. The right bundle was intact.

\section{CASE 2}

The youngest son of the patient in case 1 was born in 1952. Although asymptomatic, he was referred to a physician because of a cardiac murmur. A splitting of the two heart sounds, a third heart sound, a soft systolic ejection murmur, and a mild diastolic murmur at the left sternal border were heard. The electrocardiogram showed sinus rhythm with supraventricular extrasystoles, first degree atrioventricular block ( $P R$ interval $0.35 \mathrm{~s}$ ), and incomplete right bundle branch block.
At cardiac catheterisation, normal pressures in the heart chambers and a moderate left to right shunt of 1.65:1 at atrial level were found. Withdrawal of a pacing electrode from the right ventricle to the right atrium showed an electrical pressure pattern consistent with Ebstein's anomaly. ${ }^{12}$

Left atrial angiography detected a secundum atrial septal defect. The right ventricular angiogram showed a displaced tricuspid valve, demarcating an atrialised and a functional right ventricle. There was moderate tricuspid regurgitation (grade II). In 1978, the patient became dyspnoeic on exertion and in 1980 was referred for further evaluation.

Physical examination showed no cyanosis. His blood pressure was $120 / 80 \mathrm{~mm} \mathrm{Hg}$ and his pulse regular at 44 beats/min. Heart sounds were unchanged. The electrocardiogram showed the absence of $P$ waves, and regular ventricular complexes occurred at a rate of 40 beats/min with a complete right bundle branch block pattern. Continuous electrocardiographic monitoring showed heart rates ranging from 22 to 120 beats/min without $P$ waves and an episode of ventricular tachycardia. An electrophysiological study showed a complete absence of atrial activity (Fig. 3). Right atrial pacing with stimuli of up to $15 \mathrm{~mA}$ and pulse width up to $2 \mathrm{~ms}$ did not result in atrial capture. Lack of atrial activity and atrial inexcitability indicated atrial standstill. ${ }^{13} \mathrm{~A}$ permanent pacemaker was inserted leading to the disappearance of symptoms.

$M$ mode echocardiography showed a delay in closure of the tricuspid valve of $70 \mathrm{~ms}$ compared with mitral valve closure. Cross sectional echocardiography showed inferior displacement of $14 \mathrm{~mm}$ of the septal tricuspid leaflet in the apical four chamber view. The tricuspid valve was slightly thickened, and the anterior and septal leaflets were tethered to the right ventricle.

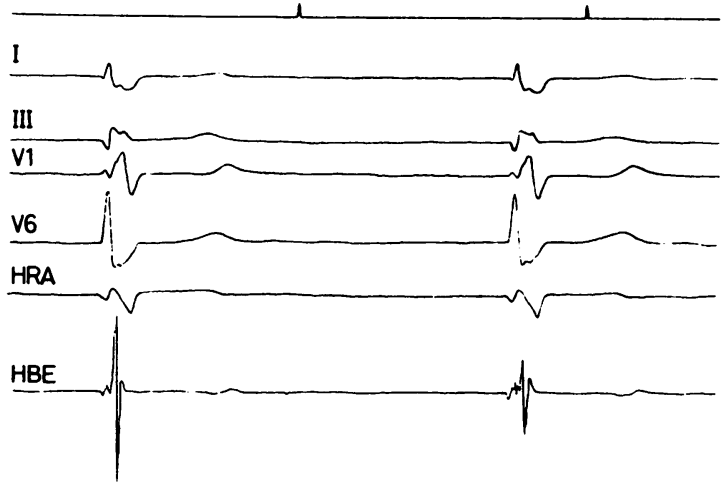

Fig 3 Simultaneous electrocardiogram, high right atrium (HRA) electrogram, and His bundle electrogram (HBE) showing the complete absence of atrial activity. 


\section{Discussion}

Atrial standstill is characterised by the absence of $P$ waves on the standard and endocavitary electrocardiograms, a slow, regular, supraventricular escape rhythm, a lack of atrial excitability, and an absence of atrial contraction and atrial pressure changes. ${ }^{14}$ Atrial standstill may be transient or persistent. Persistent atrial standstill is a rare condition. A review of published reports identified 23, of which 15 were isolated cases. A familial occurrence has been reported in a small mountain community in which marriages between siblings had often taken place over several generations. ${ }^{7}$ To our knowledge, this is the first case reported in association with Ebstein's anomaly.

The proposed mechanisms for atrial standstill include atrial degenerative disease ${ }^{15}$ or combined atrial and bundle branch disease, ${ }^{13}$ such as in our case. In this respect the haemodynamic stress induced by the tricuspid anomaly, such as in rheumatic tricuspid disease, may have produced the abnormalities seen in both the atrial wall and the His bundle. The associated atrioventricular bundle abnormalities contributed to the slow escape rhythm.

Familial Ebstein's disease is rare, ${ }^{8-10}$ and the anomaly is best considered as a failure of delamination of the septal leaflet. It is therefore not surprising for the atrioventricular bundle to be located above the valve attachment, as in our case.

It cannot be excluded that some of the $\mathbf{4 0}$ patients with persistent atrial standstill previously reported could have had a mild form of Ebstein's anomaly. In fact, because of the absence of electrical atrial activity, intracavitary electrocardiographic and pressure relations are difficult to interpret. A right ventriculogram was rarely performed in the reported cases. Cross sectional echocardiography was not performed in the recent reports. This technique seems, however, to be the most useful in diagnosing the milder forms of Ebstein's anomaly. ${ }^{16} 17$ We suggest that patients with persistent atrial standstill should be examined by cross sectional echocardiography in the four chamber view to detect dysplasia of one or two atrioventricular valves. ${ }^{18}$

\section{References}

1 Watson H. Natural history of Ebstein's anomaly of tricuspid valve in childhood and adolescence. An international cooperative study of 505 cases. Br Heart $\mathcal{F} 1974$; 36: 417-27.

2 Lev M, Gibson S, Miller RA. Ebstein's disease with Wolff-Parkinson-White syndrome. Am Heart f 1955; 49: 724-41.

3 Smith WM, Gallagher JJ, Kerr CR, et al. The electrophysiologic basis and management of symptomatic recurrent tachycardia in patients with Ebstein's anomaly of the tricuspid valve. Am $\mathcal{F}$ Cardiol 1982; 49: 1223-34.

4 Rossi L, Thiene G. Mild Ebstein's anomaly associated with supraventricular tachycardia and sudden death: clinicomorphologic features in three patients. Am $\mathcal{f}$ Cardiol 1984; 53: 332-4.

5 Allensworth DC, Rice GJ, Lowe GW. Persistent atrial standstill in a family with myocardial disease. Am $\mathcal{F}$ Med 1969; 47: 775-84.

6 Harrison WH Jr, Derrick JR. Atrial standstill: a review and presentation of two new cases of familial and unusual nature with reference to epicardial pacing in one. Angiology 1969; 20: 610-7.

7 Disertori M, Guarnerio M, Vergara G, et al. Familial endemic persistent atrial standstill in a small mountain community: a review of eight cases. Eur Heart $\mathcal{F} 1983$; 4: 354-61.

8 Gueron M, Hirsch M, Stern J, Cohen W, Levy MJ. Familial Ebstein's anomaly with emphasis on the surgical treatment. Am f Cardiol 1966; 18: 105-11.

9 Donegan CC Jr, Moore MM, Wiley TM Jr, Hernandez FA, Green JR Jr, Schiebler GL. Familial Ebstein's anomaly of the tricuspid valve. Am Heart f 1968; 75: 375-9.

10 Bialostozky D, Horwitz S, Espino-Vela J. Ebstein's malformation of the tricuspid valve. A review of 65 cases. Am $\mathcal{F}$ Cardiol 1972; 29: 826-36.

11 Rossi L. Histopathological features of cardiac arrhythmias, Milan: Case Editrice Ambrosiana, 1969: 59-62.

12 Watson $\mathrm{H}$. Electrode catheters and the diagnosis of Ebstein's anomaly of the tricuspid valve. Br Heart $\mathcal{F} 1966$; 28: 161-71.

13 Rosen KM, Rahimtoola SH, Gunnar RM, Lev M. Transient and persistent atrial standstill with His bundle lesions. Electrophysiologic and pathologic correlations. Circulation 1971; 44: 220-36.

14 Combs DT, Bellaci HF, Shively HH, Gregoratos G. Persistent atrial standstill. Am F Med 1974; 56: 231-6.

15 Lekieffre J, Asseman P, Thery CI, et al. La paralysie auriculaire permanente: ses rapports avec la maladie de l'oreillette. Ann Cardiol Angliol (Paris) 1979; 28: 235-43.

16 Gussenhoven WJ, Spitaels SEC, Bom N, Becker AE. Echocardiographic criteria for Ebstein's anomaly of tricuspid valve. $B r$ Heart $\mathcal{f}$ 1980; 43: 31-7.

17 Shiina A, Seward JB, Edwards WD, Hagler DJ, Tajik AJ. Two-dimensional spectrum of Ebstein's anomaly: detailed anatomic assessment. $\mathcal{A}$ Am Coll Cardiol 1984; 3: 356-70.

18 Daliento L, Nava A, Fasoli G, Mazzucco A, Thiene G. Dysplasia of the atrioventricular valves associated with conduction system anomalies. Br Heart f 1984; 51: 24351 . 